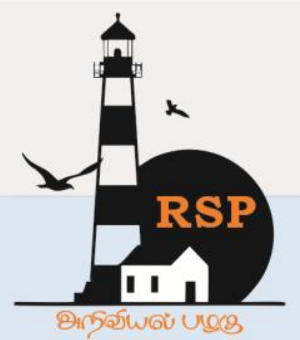

INTERNATIONAL RESEARCH JOURNAL ON ADVANCED SCIENCE HUB

\title{
Synthesis and Mechanical Analysis of on iron powder of mixed glass fiber reinforced polymer composite Material
}

B.Aravinth ${ }^{1}$, G.Vivek ${ }^{2}$, S.Gokulakrishanan ${ }^{3}$, D.Manikandan ${ }^{4}$

123,4 Assistant Professor, Dept.of Mechanical Engineering, Dr.NNCE, Tholudur, Tamilnadu, India arbu.aravinth@gmail.com ${ }^{1}$

\begin{abstract}
The present work reinforces material for polymer composites alternative to the use of Epoxy resin LY556, Glass - Woven and Chopped. The hybrid composite material is a combination of two or more different types of fiber in which one types of fiber balance the deficiency of other filler. Iron powders are used as a filler material. The composite laminates were fabricated by varying weight percentage of $0,1,3, \& 5$ of Filler material using hand layup technique. The mechanical properties of the prepared composites materials were characterized in terms of tensile strength and impact (Izod) tests as per ASTM standards. At addition of $3 \mathrm{wt}$. \% of iron powder the tensile strength was improved by $44 \%$ and impact strength by $94.2 \%$ when compared with neat polymer composites. The reason for the enhancement was wonderful interfacial bonding with fiber and polymer matrix.
\end{abstract}

Keywords: Epoxy resin, glass fiber, iron power, hand layup technique.

\section{Introduction}

The Composites materials is one in Were the materials made from more than Two materials constituent materials with considerably altered physical or chemical properties, that when joint, produce a material with typical different from the specific components. The innovative material may be wished for many applications since the materials are heavy-duty, lighter or fewer expensive when compared to old-style materials. Composites are highly targeted engineering material contains of binary or more distinct phases one is matrix phases and bordering is reinforcement phases. Polymer matrix composites (PMCs) are comprised of a variety of short or constant fibers bound together by an living polymer matrix.

The purpose of the matrix is to bond the fibers composed and to transfer loads sandwiched between them. Chief between the advantages of PMCs is their light weightiness coupled with high Stiffness then strength along the track of the reinforcement were mixture is the basis of their worth in aircraft, automobiles, and other moving organizations. Other desirable properties include greater corrosion and fatigue fight related to metals

\section{Specimen Fabrication}

\subsection{Selection of material}

\begin{tabular}{|c|l|}
\hline \multirow{2}{*}{ Matrix } & Epoxy resin LY556 \\
\cline { 2 - 2 } & Hardener HY 951 \\
\hline \multirow{2}{*}{ Fiber } & $\begin{array}{l}\text { Glass - Woven and } \\
\text { Chopped }\end{array}$ \\
\hline Fillers & Iron powder \\
\hline
\end{tabular}

Epoxy resin LY 556 with hardener HY 951 was castoff as the material of matrix. The reinforcement material used is glass fiber which is in the method of Chopped Strand Mat (CSM) and Woven Roving Mat - (WRM). 


\subsection{Fabrication}

1. The initially step in the manufacture process the diffusion of Iron powder into the Epoxy Resin LY556

2. The Patten were prepare with iron solid rod.

3. The Iron powder was mixed into the epoxy resin and the mixture is stirred for $2 \mathrm{hrs}$.at 800 rpm using high speed mechanical stirrer.

4. Then curing agent is used in stoichiometric ratio with respect to the epoxy resin.

5. These combinations which consist of Epoxy Resin LY556, Iron powder and curing agent had been applied over the glass fiber which has been cut to the size of $(500 \mathrm{~mm} * 500 \mathrm{~mm})$.

6. A layer of resin which was set firstly was functional uniformly on the upper of the fiber.

7. Roller was then pragmatic onto the surface of mat to reach uniform dispersal of mixture into the fiber glass, and also support to eliminate the air soapsuds.

8. Next films of chopped fiber mat were laid, and yet again uniform coat of resin was functional, followed by proper rolling.

9. Then process was recurrent till 4 Woven Mat and 4 Chopped fiber mats were laid one over the other.

10. And the protect was allowable to cure for 48 hr. Post-curing was approved out at $100^{\circ} \mathrm{C}$ for $6 \mathrm{hr}$ and supplementary cooled to area temperature.

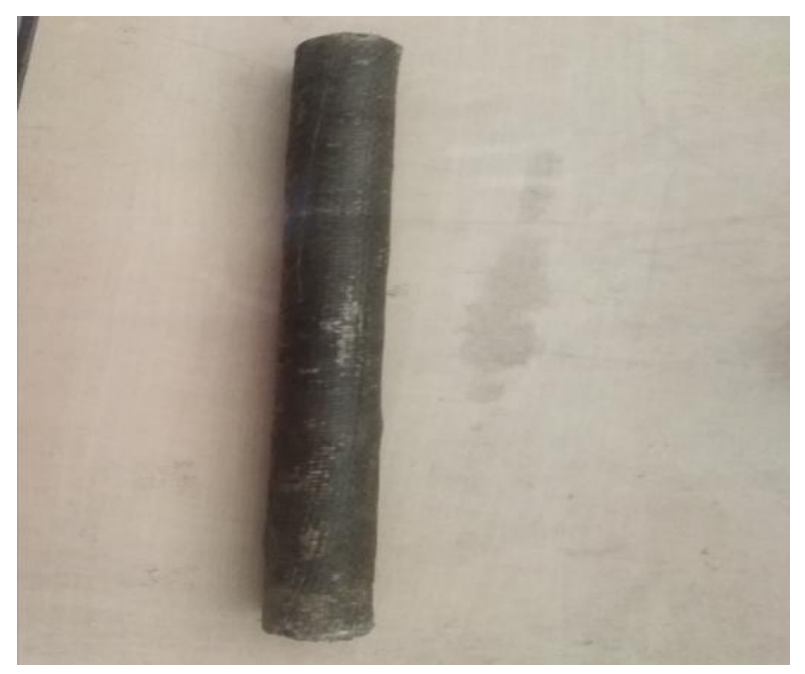

Fig. 1. Fabricated specimen

\section{Testing \& Results}

\subsection{Tensile Test}

The parameters such as ultimate strength, maximum elongation, poison`s ratio and yield strength were obtained by the stress - strain curve drawn for the tensile test of prepared laminates. Tensile tests were carried out by using INSTRON universal testing machine 3382 model under a static load of $1 \mathrm{kN}$. The tensile strength and modulus values of mixture Glass fibre reinforced epoxy / iron particles composite is open in table. 1.

Table. 1. Tensile properties of hybrid glass fiber lepoxy iron powder composites.

\begin{tabular}{|c|c|c|c|}
\hline $\begin{array}{c}\text { Iron } \\
\text { powder } \\
\text { content } \\
\text { (wt. \%) }\end{array}$ & $\begin{array}{c}\text { Maximum } \\
\text { load (N) }\end{array}$ & $\begin{array}{c}\text { Tensile } \\
\text { strength } \\
\text { (N/mm }\end{array}$ & $\begin{array}{c}\text { Tensile } \\
\text { modulu } \\
\text { s (GPa) }\end{array}$ \\
\hline 0 & 7765.77 & 64.4 & 2.91 \\
\hline 1 & 9525.38 & 79.66 & 3.19 \\
\hline 3 & 14087.61 & 114.5 & 4.04 \\
\hline 5 & 8899.44 & 80.1 & 3.78 \\
\hline
\end{tabular}

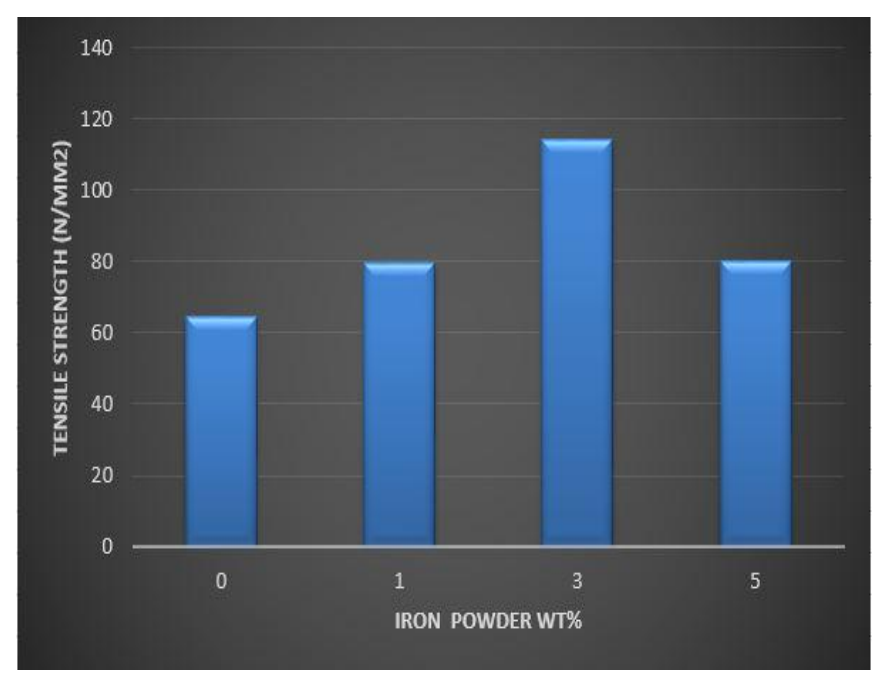

Fig. 2. Iron powder particles content (wt. \%) vs. tensile strength $\left(\mathrm{N} / \mathrm{mm}^{2}\right)$ and tensile modulus (GPa).

The graphical representation of tensile strength and tensile modulus values are sown in fig.1. It indicates the tensile strength was improved by 
www.rspsciencehub.com

$43 \%$ at adding of $3 \mathrm{wt} \%$ of Iron powder when compared with neat polymer matrix syntheses. This enhancement is owing to occurrence of exfoliated composites assembly i.e. fine dispersion of Iron powder in the polymer matrix composite. The related trend was detected in tensile modulus material goods which improved in $8 \%$ and $27 \%$ with addition of $1 \mathrm{wt} \%$ and $3 \mathrm{wt} \%$ of Iron powder respectively. But during $5 \mathrm{wt} \%$ concentration of Iron powder, it does not progress high level of tensile properties. Thus phenomenon capacity be due to the moderately reduced dispersal of Iron powder in epoxy and more probably of the existence of voids and colloidal method in the composites.

\subsection{Impact Test}

Low velocity impact test of the composite laminates could occur in the range of $1-10 \mathrm{~m} / \mathrm{s}$ contingent in the mark stiffness, material chattels and projectile mass and stiffness. Izod impact test was low velocity impact testing process that used pendulum type impact tester. The impact strength of the polymer composites laminates was measured in accordance to the ASTM standard D256 and impacted upon by energy of $1 \mathrm{kN}$. 6 pair of specimens were used to get average values from the obtained of six results. Less velocity impact strength values of hybrid fiberglass reinforced Epoxy/ Iron powder composites were presented in table 2. The obtained results showed that there was an regular increase in impact strength since $33.52 \mathrm{~kJ} / \mathrm{m}^{2}$ for neat epoxy to $94.2 \mathrm{~kJ} / \mathrm{m}^{2}$ in $3 \mathrm{wt} . \%$ of Iron powder particles infused samples.

Table. 2. Impact properties of hybrid glass fiber /epoxy Iron powder composites.

\begin{tabular}{|c|c|c|}
\hline $\begin{array}{c}\text { Iron powder } \\
\text { content (wt. \%) }\end{array}$ & $\begin{array}{c}\text { Impact meter } \\
\text { reading } \mathbf{( J )}\end{array}$ & $\begin{array}{c}\text { Impact } \\
\text { strength } \\
\left(\mathbf{k J} / \mathbf{m}^{\mathbf{2}}\right)\end{array}$ \\
\hline 0 & 4.04 & 32.3 \\
\hline 1 & 4.11 & 36.6 \\
\hline 3 & 5.58 & 94.2 \\
\hline 5 & 4.23 & 46.6 \\
\hline
\end{tabular}

The graphical representation of impact strength was exposed in fig.2. The fiber Reinforced polymer coats give rise to four modes of disappointment, matrix mode, delamination mode fiber mode and infiltration in low velocity impact .
Graphical representation of impact strength is shown in fig 2. It indicates that the impact strength was increased by $64.7 \%$ at addition of $3 \mathrm{wt}$. \% of Iron powder when compared with neat epoxy composites laminate. This result was obtained due to the uniform dispersion of Iron powder particles among the hybrid glass fibers.

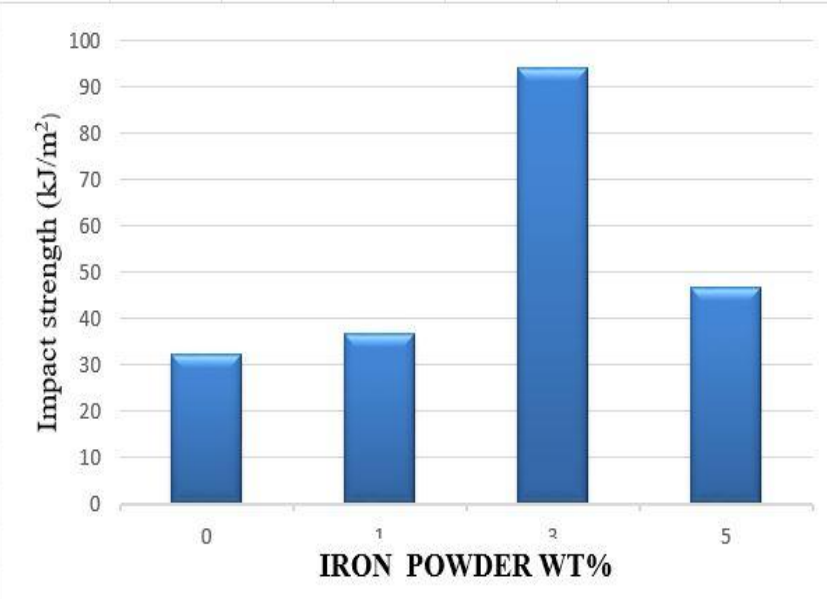

Fig. 3. Iron powder particles content (wt. \%) vs. impact strength $\left(\mathrm{kJ} / \mathrm{m}^{2}\right)$.

\section{Conclusion}

In this reading, the properties of iron particles on the hybrid glass fiber/epoxy composite coats were studied under tensile and low velocity impact tests. The following conclusions can be drawn from the tests,

- The hybrid glass fiber/epoxy iron particles composite laminates were successfully prepared by varying wt. $\%$ of $0,1,3$, and 5 respectively.

- In this work gradually growth in tensile strength and maximum tensile strength of $114.5 \mathrm{~N} / \mathrm{mm}^{2}$ is obtained at addition of $3 \mathrm{wt} \%$ of iron particles. Also maximum impact strength of $94.2 \mathrm{~kJ} / \mathrm{m}^{2}$ is observed due to the uniform load distribution on the composite laminates.

\section{Acknowledgement:}

I Would like to thank Dr.A.Thiagarajan to give this idea model to prepare the Research work and hearty Dr.K.Velmurugan 


\section{References:}

[1].Basavarajappa.S, K.V. Arun, J. Paulo Davim, "Effect of Filler Materials on Dry Sliding Wear Behaviour of Polymer Matrix Composites - A Taguchi Approach", Journal of Minerals \&Materials Characterization \& Engineering, 2009;8(5):379-391.

[2].Chittaranjan Deo and S.K. Acharya, "Effect of fiber content on abrasive wear of Lantana Camara fiber reinforced polymer matrix composite" Council of scientific and industrial research, 2010; 17: 219-223.

[3].Hasim and NihatTosunthe, "Effect of load and speed on the wear behavior of woven glass fabrics and aramid fiber-reinforced composites", Wear 2002;252(11-12): 979-984.

[4].Baljit Singh, Neel Kanth Grover, Jwala Parshad Singla "Wear behavior of GI250 grade of grey cast iron coated by $\mathrm{WC}-12 \mathrm{CO}$ and Stellite-6 coatings" International Journal of Modern Engineering Research, 2012 ;5(2):3232- 3236.

[5].BressanaJ.D., D.P. Darosa, A. Sokolowskib, R.A.Mesquitac, C.A. Barbosad, "Influence of hardness on the wear resistance of $17-4 \mathrm{PH}$ stainless steel evaluated by the pin-on-disc testing" Journal of material processing and technology,2000 